\title{
Medical knowledge in a social world: Introduction to the special issue
}

\author{
Bennett Holman' ${ }^{1}$. Sven Bernecker ${ }^{2,3}$. \\ Luciana Garbayo 4
}

Received: 9 December 2017 / Accepted: 3 April 2018 / Published online: 16 April 2018

(C) Springer Science+Business Media B.V., part of Springer Nature 2018

\begin{abstract}
Philosophy of medicine has traditionally examined two issues: the scientific ontology for medicine and the epistemic significance of the types of evidence used in medical research. In answering each question, philosophers have typically brought to bear tools from traditional analytic philosophy. In contrast, this volume explores medical knowledge from the perspective offered by social epistemology. While many of the same issues are addressed, the approach to these issues generates both fresh questions and new insights into old debates. In addition, the broader purview offered by social epistemology opens up opportunities to address new topics such as the role of consensus conferences, epistemic injustice, the value of medical knowledge, continuing medical education, and industry funding. This article situates and summarizes the contributions to this special issue.
\end{abstract}

Keywords Social epistemology · Medical epistemology · Industry-funded science · The Russo-Williamson thesis · Translational medicine · Inductive risk · Epistemic risk - Infertility · Epistemic injustice - Disorder of sex development internal morality · Medical ethics $\cdot$ Clinical decision-making $\cdot$ Implicit trust

Philosophy of medicine, as it has been developed, has addressed two primary issues. The first is establishing a scientific ontology for medicine. Such debates can pertain to

Bennett Holman

bholman@yonsei.ac.kr

1 Underwood International College, Yonsei University, 85 Songdogwahak-ro, Yeonsu-gu, Incheon 21983, South Korea

2 University of California, Irvine, Irvine, USA

3 University of Cologne, Cologne, Germany

4 University of Central Florida, Orlando, USA 
either the refinement of general concepts (e.g. the boundaries of health, disease, illness, and sickness) or of nosological classification (e.g. psychiatric disorders). Aside from ontology, philosophers of medicine have also focused on the kinds of evidence used in medical research and what degree of confirmational significance is warranted by various methods. In answering each question, philosophers have typically brought to bear tools from traditional analytic philosophy.

A clear example of the first issue is illustrated in the Boorse-Wakefield debate over whether the concept of disease can be naturalized. Classically, Boorse (1976) argues that a disease necessarily involves the disruption of a natural function; whereas, Wakefield (1992) argues that not only must there be a dysfunction, but that there must be harm-a social judgment that the dysfunction is undesirable. However, as Dominick Murphy (2006, p. 21) has pointed out, both parties in the debate are committed to the "orthodox program" that "conceptual analysis establishes what counts as the subject matter of inquiry and the restraints under which inquiry should precede."

Though ostensibly engaged in empirical projects, Murphy (2006) claims that all parties have been doing newfangled conceptual analysis. While Murphy's description may fit some arguments (e.g. Wakefield 2000), it is not the whole story. For example, it fails to account for arguments which draw extensively upon the history of medicine (e.g. Horwitz 2002) and which engage with empirical science (e.g. Spitzer and Wakefield 1999). Nevertheless, what is essentially correct about Murphy's critique is that the focus of the debate revolves around sharpening the definition of a general concept (e.g. disease, health, etc.). More recent extensions of this debate include contributions from Cooper (2002), Hofmann (2002) and Ereshefsky (2009).

Previous work in analytic philosophy has also informed debates in medical epistemology. For example, Cartwright's (2007, 2010) critique of randomized controlled trials (RCTs) is informed by her earlier work on causal powers $(1983,1989)$. Likewise, the Russo and Williamson (2007) thesis - that in order to establish that A causes B, you need both evidence of a correlation and evidence of the mechanism by which A causes B-dovetails with Williamson's earlier work on the metaphysics of causation (Williamson 2005, esp. ch. 9). ${ }^{1}$ What these accounts share is that they abstract away from the conditions in which knowledge is produced in order to focus on the relationship between evidence and inference.

As exemplified in the contributions to this volume, many of the same issues are dealt with in social epistemology; however, the methodological approach and the types of questions being asked represent a break. In contrast to an epistemological focus on an isolated knower confronting a fixed set of evidence, social epistemology attempts to make room both for the social practices that promote knowledge and those that obscure it. The broader purview offered by social epistemology opens up opportunities for philosophers interested in medical knowledge to discuss topics such as the role of consensus conferences, epistemic injustice, the value of medical knowledge, continuing medical education, and industry funding.

\footnotetext{
1 In personal communication Williamson has noted that that Russo-Williamson thesis does not strictly depend on the Williamson's metaphysical account of causality and that though they fit together nicely, it is perfectly possible to adopt either one without being committed to adopt the other.
} 
In the contribution "Philosophers on Drugs," Bennett Holman attempts to delineate the scope of - and the need for-social epistemology in the study of medical knowledge. He begins by demarcating social epistemology from what he calls "friction-free epistemology." The latter includes any account which abstracts away from the worldly complications of how medical knowledge is produced and distributed to focus solely on abstract representations of ideal types of evidence. Importantly, Holman does not discount the importance of friction-free epistemology for answering questions about the structure and limits of inference. However, he argues that friction-free epistemology can neither answer questions regarding the evaluation of actual evidence nor should it inform policy decisions. Holman argues that because industry-funding and commercial imperatives are an entrenched and pervasive part of medical science, they must be incorporated into the evaluation of evidence, not as an afterthought, but as an integral part of the epistemic structure of medical research.

In support of the claim, Holman argues that because industry funding is so pervasive, ignoring it causes philosophers to draw the wrong lessons from cases that they take as paradigmatic for their view. As an example, Holman examines a case study that plays a prominent role in the debates regarding causation, specifically the use of class $1 \mathrm{C}$ antiarrhythmic drugs. According to Jeremy Howick's (2012) account, the drug was approved because it prevented heart arrhythmias and heart arrhythmias were found to be a frequent cause of cardiac arrests. Such reasoning supported the "antiarrhythmic hypothesis" that preventing arrhythmias should prevent cardiac arrest. Unfortunately, not only was the drug ineffective, it led to the deaths of hundreds of thousands of patients - making it possibly the largest drug disaster in history (Moore 1995). Howick argues that the problem was not the reliance of mechanistic reasoning, but the fact that the mechanistic evidence was not "high-quality."

Holman reanalyzes the case in greater detail and shows that contra Howick, the available mechanistic evidence meets Howick's standards for being high quality. Moreover, Holman argues that it was not the mechanistic theory that was driving doctors' prescription habits because even after the pivotal RCT that showed the antiarrhythmic hypothesis was false (CAST 1989), doctors kept prescribing the drugs. Instead, at multiple critical points, Holman traces how the influence of industry funding led to commercially favorable views being adopted by the medical community. As a result, philosophical accounts that take evidence at face value without concern for larger social and economic structures in which the evidence functions, fail to address the primary threats to reliable medical knowledge.

In closing, Holman considers three prominent social epistemologies (Goldman, Solomon, and Longino). After briefly summarizing each philosopher's approach, Holman shows that the account captures some important aspect of the case study that friction-free epistemology neglects. Though he ultimately concludes that no single account is sufficient (and they are mutually incompatible), he argues that they serve as useful jumping off points for future work in philosophy of medicine that aims to address practically oriented questions or address science policy.

An illustration of the fruitfulness of social epistemological analysis is provided in Mark Robinson's contribution, "Financializing Epistemic Norms in Contemporary Biomedical Innovation." Robinson begins by introducing a puzzle identified by Miriam Solomon (2015) in her book Making Medical Knowledge. There Solomon 
explores a number of "paradigms" that have arisen in medicine in response to evidencebased medicine, including the movement in medicine to usher knowledge "from bench to bedside" known as translational medicine (TrM). Her exploration of TrM leaves her underwhelmed. Despite the fact that it is clearly a rapidly growing movement within medical research, it is hard to see what is new. TrM is characterized by the goal to develop applications-based basic research, but Solomon notes, the need to turn basic science into a viable treatment is hardly a revolutionary new development. Moreover, beyond this goal, she finds that nothing that really unites TrM as a recognizable field. Thus, she echoes the concern of others (e.g. Maienschein et al. 2008; Wehling 2008) that $\operatorname{TrM}$ is little more than the clever marketing of old wine in new bottles.

What Robinson convincingly shows is that the puzzle arises from attempting to understand TrM as an epistemic problem internal to scientific research. It is only when one attends to the social and economic structures of science that one sees that TrM is at the heart of a massive restructuring of medical research. As such, Robinson tackles two intertwined questions central to social epistemological inquiry: (1) What is the social structure of the knowledge creating community and (2) How does that knowledge structure affect what knowledge is produced?

Robinson's answer to the first question rests on his argument that one way of understanding the push for TrM is as an externalization of risk for pharmaceutical companies. He traces the rise of centers for translational medicine throughout the country and shows that they are contemporaneous with massive restructuring of the internal organization of the pharmaceutical industry, particularly the gutting of in-house research and development. In short, significant portions of the work that was previously completed in the private sector is now being conducted in university-industry partnerships. Moreover, Robinson's careful study shows that this is the result of an intentional corporate strategy to lower costs by conducting the riskiest parts of drug developments in university partnerships using public funds. Indeed, the majority of the paper examines specific ways in which research infrastructure is changing to accommodate these new partnerships.

On the second question, Robinson is more general: TrM is leading to the agendas of university researchers to increasingly become guided by the commercial objectives of their industry partners. This opens up the door for future research to fill out his picture with detailed examples; however, one should not discount the extent to which Robinson's work identifies a radical departure from the incentive structure that philosophers usually presume to dominate basic research conducted within universities. For example, in his recent work on stratification within the scientific community, Remco Heesen (2017) presumes the currency of academic life to be publications and citations. This accords with the received wisdom that a "publish or perish" mentality pervades university reward structures (c.f. Bright 2017). Such a backdrop underscores the magnitude of the change being advocated by proponents of TrM: "the aim of publishing in (sic) high-profiled papers is antagonistic to a successful translational process... It may very well be the case that we need an entirely new evaluation system that recognizes the links between academic and industry [objectives]" (Chubb 2012, as quoted by Robinson).

In short, Robinson's paper provides a surprising and deeply original answer to Solomon's (2015) puzzle. What is new about TrM is not its methodology, but the way 
that TrM channels the efforts of academic researchers into producing commercially viable products. It fundamentally alters the structure and norms of academic research in ways that have downstream effects on the type of knowledge (and ignorance) that is produced. Such changes are so drastic that in other domains, similar developments have led philosophers to question whether the type of inquiry that occurs within such structures is properly classified as science (Carrier et al. 2008, esp. part 3; Carrier and Nordmann 2011; Radder 2010; Nordmann et al. 2011). For those who think that TrM is simply more of the same, an interesting project would be considering Robinson's work as it pertains to this "epochal break" thesis.

In the contribution "Infertility, Epistemic Risk, and Disease Definitions," Rebecca Kukla considers a specific example of how social considerations shape science by examining the variegated and contradictory definitions of "infertility." For example, one of the clinical definitions holds from the World Health Organization (2018) that infertility is "the inability of a sexually active, non-contracepting couple to achieve pregnancy in 1 year." Such a definition has a number of odd consequences when taken literally. For example, it follows from this definition that one cure for infertility would be to end the relationship and another would be to begin using contraception. However, what these oddities reveal is that the definitions are not grounded solely in medical issues, but social interests that are being embedded within definitions of pathology.

One social force acting in this context stems from questions of who is deserving of access to assisted reproductive techniques. For example, at its most restrictive, infertility is defined as: "the inability of those of reproductive age (15-49 years) to become or remain pregnant within 5 years of exposure to pregnancy." In contrast, the most permissive definition includes people who are childless because they cannot find a sexual partner (Bodkin 2016). As Kukla notes, the function of the definition is to create an entitlement to reproductive assistance for single people who want a family. It also has the function of pathologizing unwanted singlehood. ${ }^{2}$

Indeed, all of the eight definitions of infertility listed by WHO have normative implications baked into them, in that they serve to normalize heterosexual family life in which children are biologically related to their parents. It follows that deviations from this "normal" state, such as same-sex partnerships, are infertile and pathological. However, for Kukla, it is not the fact that values are embedded within the definition of infertility that creates the problem. Following Heather Douglas (2000) and other recent developments in the literature on values in science, Kukla grants that in many cases our category boundaries will be value-laden. The relevant question is thus, do the boundaries of infertility group together cases in a way that serves our epistemic and practical needs; specifically, are they "useful tools when it comes to defining research questions, undergirding productive methodologies, designing treatment interventions, and aiding human flourishing?"

With this standard in mind, Kukla argues that the disease that we call "infertility" is actually a symptom she suggests calling "unwanted childlessness." Some cases of unwanted childlessness have social causes (e.g. singlehood), while others are, properly speaking, the result of medical issues (e.g. low sperm count). Lumping these together

\footnotetext{
2 WHO does not, at the time of going to press, endorse that definition. Whether they ever seriously considered adopting such expansive terms is a matter of dispute (Garcia 2016).
} 
under a single umbrella term would seem to inhibit research rather than facilitate it. Beyond this, definitions of infertility also problematically reinforce social norms around gender, sexuality, and devalue certain types of parenthood. Finally, in terms of securing access to assisted reproductive technology for a larger population, Kukla argues that demedicalizing unwanted childlessness allows for a more straightforward discussion of the topic and opens up non-medical alternatives (e.g. adoption).

Teri Merrick's contribution considers another case of contested medical diagnosis in 'From 'Intersex' to 'DSD': A Case of Epistemic Injustice." Merrick uses the philosophical tools afforded by Fricker's $(2007,2010)$ theory of epistemic injustice to analyze the shift in nomenclature from "intersex" to "disorder of sex development (DSD)." Merrick argues that the label embeds the judgment that bodies that fail to meet a normative binary division between male and female are unnatural and in need of medical intervention. This, she claims, can be understood as an example of hermeneutic injustice.

According to Fricker (2007) hermeneutic injustice occurs when a group of people are systematically prevented access to the institutions in society in which meaning is made. As a result of this exclusion, members of the excluded group lack the concepts needed to make sense of their own experience. With sufficient organization, resistant discourses can emerge which facilitate understanding for individuals with access to the underground literature; however, even in these cases, members will face difficulty communicating their experience to mainstream audiences (Dotson 2012). In such cases, Fricker (2010) argues that epistemic justice can be achieved if members of the epistemic community with power adopt the corrective virtue of "active silence" in which they seek out and incorporate the experiences of seldom heard voices. It was this corrective virtue that Merrick argues was lacking in the cases of creating the DSD label.

Her argument begins by exploring the history of the "optimal gender" treatment model, which prescribed that in cases where the infant's sex characteristics failed to conform to the male/female binary, surgical intervention was recommended to "assign" the infant a sex and the corresponding gender role (i.e. dress, heterosexual partnership, etc.) (Karkazis 2008). Prejudice against children with non-conforming bodies is one of the main motivating forces in these cases. In fact, parents are often encouraged to keep the surgeries a secret from their children so as not to encourage "confusion".

In light of current treatment regimens, patient advocates campaigned for three changes: (1) an end to the binary construction of sex and incorporation of nonconforming bodies as part of natural variation; (2) use of surgeries only if there was a threat to patient health; (3) incorporating the patient into decision making, thus ending the practice of concealing the diagnosis from the patient. Especially given the first aim, it is clear that the 2005 consensus statement which included the reclassification of children from "intersex" to having a "disorder of sex development" fails to realize the goals of patient advocacy groups. As Merrick goes on to show, patient advocacy groups acquiesced to the term because using it allowed them access to "big players" in biomedicine. As further evidence, Merrick notes that amongst the literature that circulates within patient advocacy groups, DSD is often subverted to stand for "differences of sexual development." 
Furthermore, the effect of the 2005 consensus statement has been equivocal. Though it incorporated the second and third recommendations, significant portions of the medical community continue to support early surgical intervention. Yet rather than blame medical practitioners, Merrick faults larger epistemic structures that prevented the patient voice from being heard. Crucially, the disposition to medicalize a societal prejudice. Given that society will reject and ostracize people with non-typical bodies, rather than work to end social prejudice, the medical community chose to pathologize non-conforming bodies and work to surgically bring them into line with what society will accept. The fact that this disposition remains even after consulting with patient groups underscores Merrick's conclusion: Merely providing a role for patient advocates is not necessarily sufficient to prevent epistemic injustice.

A positive procedure that would satisfactorily incorporate the patient voice into the internal morality of medicine is proposed in "The internal morality of medicine: A constructivist approach" a contribution from Nir Ben-Moshe. He notes that a rejection of medical paternalism has arisen from the recognition that to make medical judgments, doctors must know the values of their patient. Yet the hope that a doctor can be a provider of neutral facts presupposes that facts can be cleanly separated from values. Moreover, it has been recognized that allowing patients full autonomy can lead patients to make choices that frustrate their values. This has led to the shared decision making model which reintroduces the need for doctors to make value judgments, but this time with the active participation of the patient. Accordingly, it also reintroduces the need to identify a foundation for a doctor's value-judgements.

Following Pellegrino (1999), Ben-Moshe argues that the proper source of medicine's values are internal to medical practice and stem from the goal of healing. He proposes that the foundation of medical morality stems from the "Fundamental Idea" that a good physician has mastered the skills, knowledge, and epistemic virtues that facilitate their raison d'etre, to heal the patient. Where he breaks from Pellegrino is in his denial of moral realism. Rather than morality existing in the external world independent of human's appreciation of it, Ben-Moshe advocates "an account of an internal morality of medicine that can interact with and incorporate some of the relevant sources of values outside of it."

Here he turns to the work of Franklin Miller and Howard Brody who hold that there is a core ethic of medicine that develops as medicine interacts with society. Whereas this process of revaluation has been applied to controversial cases such as physicianassisted suicide (Miller and Brody 1995); managed care (Brody and Miller 1998), and cosmetic surgery (Miller et al. 2000), no one has yet articulated a general procedure for developing medicine's internal morality.

Ben-Moshe's suggestion is that the construction of medicine's internal morality begins from the basic goal of "benefitting patients in need of prima facie medical treatment and care." While this serves as a jumping off point, it must still be further constructed in dialogue with the various stakeholders in medicine. Of note, while doctors and patients might be accorded some elevated status, other stakeholders such as medico-legal scholars and philosophers are still part of the discussion. The latter are qualified not only by their special training and unique expertise, but also because their remove offers an important perspective on medical morality which may lead to 
greater impartiality. The outcome of the deliberation is the norms that should guide practice in light of its basic goal.

In contrast to being a hypothetical procedure to prime our ethical intuitions, BenMoshe is clear that he is offering an actual procedure that could be engaged into determine medical morality and one that, if properly carried out, would then be binding on the profession. What is attractive about Ben-Moshe's account is that it incorporates patient values within the internal morality of medicine, rather than patient values being something that medical morality must be reconciled with (as in Miller and Brody (1995)). In Ben-Moshe's constructive discussion, doctors are considered experts of how interventions will impact the patient and the patient is ceded expertise on the degree to which they value those outcomes. This is because though the "physician might be the expert when it comes to the patient's medical good, it is the patient who has intimate knowledge of his perception of the good." Nevertheless, it is only in discussion that the proper action can be (jointly) determined. This determination does not stand apart from medical morality, but is constitutive of it.

In the final contribution to the special issue, Sophie van Baalen and Annamaria Carusi examine how trust functions in the group creation of knowledge. Via a detailed case study of image assisted diagnosis and treatment of pulmonary hypertension, the paper tracks how trust evolves in a medical team as they develop shared ways of interpreting the evidence. They argue that trust is not necessarily preceded by reasons to trust someone's expertise, skill or proficiency at a task; rather reasons and trust are instead interwoven.

Emerging from their case study, they find that reasons are formed during the process of "establishing criteria for jointly carving out tasks." These epistemic frameworks develop by repeatedly adjusting and calibrating interpretations in relation to others, establishing what counts as evidence, and ranking different kinds of evidence to establish "a joint space of reasons." Through an iterative process of repeated interactions, team members converge on orientations towards evidence. It is this process of establishing and cultivating a shared space of reasons that provides a framework in which interpretations and justifications can be shared.

Ultimately, van Baalen and Carusi claim that what counts as a reason for trust in the expertise and competence of others is established indirectly, while attending to other things besides trust itself. Instead, in the meetings they observed, a main focus of the group is generating agreement. In this process experts from different fields with different expertise forge a shared orientation to the evidence. As the group generates a history of interacting and collaborating, they begin to agree, for example, what part of a CMRI image is relevant to diagnosis. This shared orientation forms the grounds for trusting in other's judgment and is reinforced by ongoing negotiations over how the images should be produced, processed, and analyzed. In so doing, they create a common stock of reasons to accept or reject evidence that the giver and receiver of testimony accept. These, in turn, form the reasons for trusting an instance of testimony from another team member. Van Baalen and Carusi's account is neither reductionist nor anti-reductionist, but rather a holist account of trust in which trust and reasons for trust develop simultaneously in situations of epistemic dependence, not overtly, but implicitly while attending to the task at hand. 
Stepping back from these individual contributions, it is worth noting three features shared by multiple papers. The first is that traditional topics from philosophy of medicine remain, though the types of questions asked within these domains are different. Rather than seek to define the concept of disease, the questions addressed by Kukla and Merrick pertain to the legitimacy of particular disease categories. Similarly, rather than consider medical trials in the abstract Holman's paper explores close inspection of the specific research that supported the treatment of heart arrhythmias. Thus, one might be tempted to cast the difference between traditional and social epistemology as whether one focusses on the general or the particular. This, we think, would be a mistake.

Such a division would neglect, for example, Ben-Moshe's general account of incorporating patient values into the internal morality of medicine and the extent to which van Baalen and Carusi's account of the functioning of trust is meant to speak to the functioning of trust more generally. Likewise, the social epistemological frameworks discussed by Holman are certainly meant to be general. Instead, what counts for the particularity appears to be methodological. More so than is typical for works of philosophy, social epistemology is frequently informed by detailed and empirically grounded case studies. This can be said not only of Holman and Merrick's papers, but even more so for both Robinson and van Baalen and Carusi's papers whose arguments arise from detailed field observations performed by the authors themselves.

This sensibility is not surprising given that prominent strains of social epistemology have their intellectual roots in attempts to resolve the disputes between philosophers of science and sociological/anthropological studies of science that led to the "Science Wars." One of the critiques that Goldman (1999), Solomon (2001) and Longino (1990) all accept is that traditional approaches to philosophy of science were not well-grounded in the realities of scientific inquiry. Accordingly, the first commonality (a focus on the particular) is not essential, but rather an outgrowth of the second (the methodological reliance on detailed case studies).

Nevertheless, one should not lose sight of the fact that as a result, the markers of legitimacy have changed. For example, in the case of whether infertility or DSD are diseases, at no time do Kukla or Merrick rest an argument on the fact that adopting one definition over another violates their intuitions regarding the nature of disease. Instead the argumentative force comes from the fact that category fails to serve our pragmatic ends (Kukla) or that procedure used to generate the category was unjust (Merrick).

The final commonality is the cross-fertilization that occurs at the intersection of medical and social epistemology. Holman argues that social epistemology can bring new insight to pressing questions in the philosophy of medicine and no doubt, this is evidenced by many of the contributions. However, what should not be lost is that, as the contributions of Kukla and van Baalen and Carusi demonstrate, studies in the philosophy of medicine also have the potential to inform debates in social epistemology. We hope that, if nothing else, this special issue provides evidence of the fruitfulness at the intersection of these two fields. 


\section{References}

Bodkin, H. (2016). Single men will get the right to start a family under new definition of infertility. The Telegraph. Retrieved from https://www.telegraph.co.uk/news/2016/10/19/single-men-will-get-the-rightto-start-a-family-under-new-defini/.

Boorse, C. (1976). What a theory of mental health should be. Journal for the Theory of Social Behaviour, 6, 61-84.

Bright, L. K. (2017). Decision theoretic model of the productivity gap. Erkenntnis, 82, 421-442.

Brody, H., \& Miller, F. G. (1998). The internal morality of medicine: Explication and application to managed care. Journal of Medicine and Philosophy, 23, 384-410.

Carrier, M., Howard, D., \& Kourany, J. A. (Eds.). (2008). The challenge of the social and the pressure of practice: Science and values revisited. Pittsburg, PA: University of Pittsburgh Press.

Carrier, M., \& Nordmann, A. (Eds.). (2011). Science in the context of application: Methodological change, conceptual transformation, cultural reorientation. Dordrecht: Springer.

Cartwright, N. (1983). How the laws of physics lie. New York, NY: Oxford University Press.

Cartwright, N. (1989). Nature's capacities and their measurement. Oxford: Oxford University Press.

Cartwright, N. (2007). Are RCTs the gold standard? Biosocieties, 2, 11-20.

Cartwright, N. (2010). What are randomized controlled trials good for? Philosophical Studies, 147, 59-70.

CAST Investigators. (1989). Preliminary report: Effect of encainide and flecainide on mortality in a randomized trial of arrhythmia suppression after myocardial infarction. New England Journal of Medicine, $321,406-412$.

Cooper, R. (2002). Disease. Studies in the History and Philosophy of Biology and the Biomedical Sciences, $33,263-282$.

Dotson, K. (2012). A cautionary tale: On limiting epistemic oppression. Frontiers: A Journal of Women Studies, 33, 24-47.

Douglas, H. (2000). Inductive risk and values in science. Philosophy of Science, 67, 559-579.

Ereshefsky, M. (2009). Defining 'health' and 'disease'. Studies in History and Philosophy of Science Part C: Studies in History and Philosophy of Biological and Biomedical Sciences, 40, 221-227.

Fricker, M. (2007). Epistemic injustice: Power and the ethics of knowing. Oxford: Oxford University Press. Fricker, M. (2010). Replies to Alcoff, Goldberg, and Hookway on epistemic injustice. Episteme, 7, 164-178.

Garcia, A. (2016). Only the lonely. Snopes. Retrieved from https://www.snopes.com/fact-check/beingsingle-is-a-disability/

Goldman, A. (1999). Knowledge in a social world. New York, NY: Oxford University Press.

Heesen, R. (2017). Academic superstars: Competent or lucky? Synthese, 194, 4499-4518.

Hofmann, B. R. (2002). On the triad disease, illness and sickness. The Journal of Medicine and Philosophy, 27, 651-673.

Horwitz, A. V. (2002). Creating mental illness. Chicago, IL: University of Chicago Press.

Howick, J. (2012). The philosophy of evidenced-based medicine. West Sussex: British Medical Journal Books.

Karkazis, K. (2008). Fixing sex: Intersex, medical authority, and lived experience. Durham, NC: Duke University Press.

Longino, H. E. (1990). Science as social knowledge: Values and objectivity in scientific inquiry. Princeton, NJ: Princeton University Press.

Maienschein, J., Sunderland, M., Ankeny, R. A., \& Robert, J. S. (2008). The ethos and ethics of translational research. The American Journal of Bioethics, 8, 43-51.

Miller, F. G., \& Brody, H. (1995). Professional integrity and physician-assisted death. Hastings Center Report, 25, 8-17.

Miller, F. G., Brody, H., \& Chung, K. C. (2000). Cosmetic surgery and the internal morality of medicine. Cambridge Quarterly of Healthcare Ethics, 9, 353-364.

Moore, T. (1995). Deadly medicines: Why tens of thousands of heart patients died in America's worst drug disaster. New York, NY: Simon and Schuster.

Murphy, D. (2006). Psychiatry in the scientific image. Boston, MA: MIT Press.

Nordmann, A., Radder, H., \& Schiemann, G. (Eds.). (2011). Science transformed? Debating claims of an epochal break. Pittsburgh, PA: University of Pittsburgh Press.

Pellegrino, E. D. (1999). The goals and ends of medicine: How are they to be defined? In M. J. Hanson \& D. Callahan (Eds.), The goals of medicine: The forgotten issue in health care reform (pp. 55-68). Washington, DC: Georgetown University Press. 
Radder, H. (Ed.). (2010). The commodification of academic research. Pittsburgh, PA: University of Pittsburgh Press.

Russo, F., \& Williamson, J. (2007). Interpreting causality in the health sciences. International Studies in the Philosophy of Science, 21, 157-170.

Solomon, M. (2001). Social empiricism. Cambridge, MA: MIT Press.

Solomon, M. (2015). Making medical knowledge. Oxford: Oxford University Press.

Spitzer, R. L., \& Wakefield, J. C. (1999). DSM-IV diagnostic criterion for clinical significance: Does it help solve the false positives problem? American Journal of Psychiatry, 156, 1856-1864.

Wakefield, J. C. (1992). The concept of mental disorder: On the boundary between biological facts and social values. American Psychologist, 47, 373-388.

Wakefield, J. C. (2000). Spandrels, vestigial organs, and such: reply to Murphy and Woolfolk's 'The harmful dysfunction analysis of mental disorder'. Philosophy, Psychiatry, and Psychology, 7, 253-269.

Wehling, M. (2008). Translational medicine: science or wishful thinking? Journal of Translational Medicine, $6(1), 31$.

Williamson, J. (2005). Bayesian nets and causality: Philosophical and computational foundations. Oxford: Oxford University Press.

World Health Organization. (2018). Infertility definitions and terminology. Retrieved from http://www.who. int/reproductivehealth/topics/infertility/definitions/en/ 